\section{2}

\title{
Title: Inactivation mechanism and efficacy of grape seed extract for Human Norovirus surrogate
}

\author{
Running title: Grape seed extract inactivates Tulane viruses
}

Chamteut $\mathrm{Oh}^{1, *}$, Ratul Chowdhury ${ }^{2, *}$, Laxmicharan Samineni ${ }^{3}$, Joanna L Shisler ${ }^{4}$, Manish Kumar $^{6}$, and Thanh H. Nguyen ${ }^{1,5}$

${ }^{1}$ Department of Civil and Environmental Engineering, University of Illinois at UrbanaChampaign, USA

${ }^{2}$ Department of Chemical Engineering, The Pennsylvania State University, PA, USA ${ }^{3}$ Department of Chemical Engineering, The University of Texas at Austin, Austin, USA

${ }^{4}$ Department of Microbiology, University of Illinois at Urbana-Champaign, USA ${ }^{5}$ Institute of Genomic Biology, University of Illinois at Urbana-Champaign, USA

${ }^{6}$ Department of Civil, Architectural and Environmental Engineering, The University of Texas at Austin, Austin, USA

\section{*Equal contribution}

Corresponding author(s): Thanh H. Nguyen (thn@illinois.edu) 


\section{Abstract}

35 Proper disinfection of harvested food and water is critical to minimize infectious disease. Grape

36 seed extract (GSE), a commonly used health supplement, is a mixture of plant-derived

37 polyphenols. Polyphenols possess anti-microbial and -fungal properties, but anti-viral effects are

38 not well-known. Here we show that GSE outperformed chemical disinfectants (e.g., free chlorine

39 and peracetic acids) in inactivating Tulane virus, a human norovirus surrogate. GSE induced

40 virus aggregation, an event that correlated with a decrease in virus titers. This aggregation and

41 disinfection was not reversible. Molecular docking simulations indicate that polyphenols

42 potentially formed hydrogen bonds and strong hydrophobic interactions with specific residues in

43 viral capsid proteins. Together, these data suggest that polyphenols physically associate with

44 viral capsid proteins to aggregate viruses as a means to inhibit virus entry into the host cell.

45 Plant-based polyphenols like GSE are an attractive alternative to chemical disinfectants to

46 remove infectious viruses from water or food.

48 Keywords: polyphenols; grape seed extract; Human norovirus surrogate Tulane virus; virus 49 aggregation; Molecular docking simulations 


\section{Importance}

52 Human noroviruses are major food- and water-borne pathogens, causing approximately $20 \%$ of

53 all cases of acute gastroenteritis cases in developing and developed countries. Proper sanitation

54 or disinfection are critical strategies to minimize human norovirus-caused disease until a reliable

55 vaccine is created. Grape seed extract (GSE) is a mixture of plant-derived polyphenols that is

56 used as a health supplement. Polyphenols are known for antimicrobial, antifungal, and

57 antibiofilm activities, but antiviral effects are not well-known. In studies here, plant-derived

58 polyphenols outperformed chemical disinfectants (e.g., free chlorine and peracetic acids) in

59 inactivating Tulane virus, a human norovirus surrogate. Based on data from additional molecular

60 assays and molecular docking simulations, the current model is that the polyphenols in GSE bind

61 to the Tulane virus capsid, an event that triggers virion aggregation. It is thought that this

62 aggregation prevents Tulane virus from entering host cells.

63 


\section{Introduction}

Human noroviruses cause approximately $20 \%$ of all cases of acute gastroenteritis in

67 million cases of food borne illnesses per year, and about 2 billion dollars in economic loss $(2,3)$.

68 Noroviruses are transmitted primarily by the fecal-oral route, including ingestion of

69 contaminated food and water or via person-to-person contacts (4). Thus, inactivating human

70 noroviruses present in contaminated food or water is important.

71 Sodium hypochlorite $(\mathrm{NaClO})$ is regarded as the cheapest and most effective disinfectant

72 to inactivate noroviruses on produce surfaces (5), stainless steel surfaces (6), or in liquid

73 solutions (7). Fresh and fresh-cut produce are generally sanitized with residual chlorine

74 concentrations of 50-200 $\mu \mathrm{g} / \mathrm{mL}$ (8). Unfortunately, $\mathrm{NaClO}$ is toxic, and produces carcinogenic

75 disinfection by-products (9-11). Thus, both consumers and industry are seeking methods to

76 naturally or minimally process foods with minimal/zero chemical additives $(12,13)$.

77 Plants and fruits synthesize polyphenols, chemicals that protect them against damage

78 from external stresses such as infection. Grape seed extract (GSE) is a by-product of grape juice

79 and wine production, and is mass-produced at an affordable price $(14,15)$. GSE already is sold

80 as an FDA-approved health supplement (16). GSE polyphenols have antimicrobial effects (17)

81 and are considered popular alternatives to chemical disinfectants. GSE possesses anti-viral

82 activity against feline calicivirus (FCV-F9), murine norovirus (MNV-1), bacteriophage MS2,

83 and hepatitis A virus $(14,18,19)$. However, the mechanism of virus inactivation is unclear (16).

84 This information is critical because, if GSE is to be used by industries as a natural disinfectant,

85 then researchers must understand how GSE inactivates different types of viruses. 
The objective of this study was to examine GSE-induced inactivation of Tulane virus, a

87 surrogate for human norovirus. Tulane virus is an ideal surrogate for norovirus because of its

88 structural similarities to human noroviruses (20-22). Thus, Tulane virus has been used to provide

89 more information about potential inactivation of norovirus (7, 23-27). Once GSE disinfection

90 was established, we identified the mechanism of this inactivation using both molecular assays

91 and computer modeling. Studies showed that GSE's main disinfection action occurred due to

92 virus aggregation. Molecular docking simulations identified potential interactions between GSE

93 polyphenols and viral capsids. This study is the first observation that shows plant-derived

94 polyphenols can outperform chemical disinfectants in safely and sustainably controlling water-

95 borne and food-borne pathogens, and also provides the first mechanism for GSE-induced virus

96 inactivation. Thus, GSE may be an attractive disinfectant for industry because of its safety,

97 efficacy and lower impact on the environment.

98

99 Results

100 GSE outperforms chemical disinfectants by $3-\log _{10}$ TV titer reduction

101 Fig. 1 shows results from the examination of disinfection properties of GSE against

102 Tulane virus, using a range of different GSE concentrations, Tulane virus (TV) concentrations,

103 and incubation times. For all experiments, GSE was incubated with purified TV. GSE activity

104 was halted by the addition of FBS, and plaque-forming units (PFUs) were quantified as a

105 measure of virus inactivation. We tested GSE concentrations ranging from $42 \mu \mathrm{g} / \mathrm{mL}$ to 678

$106 \mu \mathrm{g} / \mathrm{mL}$ because similar GSE concentrations were shown to inactivate other enteroviruses $(14,18$,

107 19). 

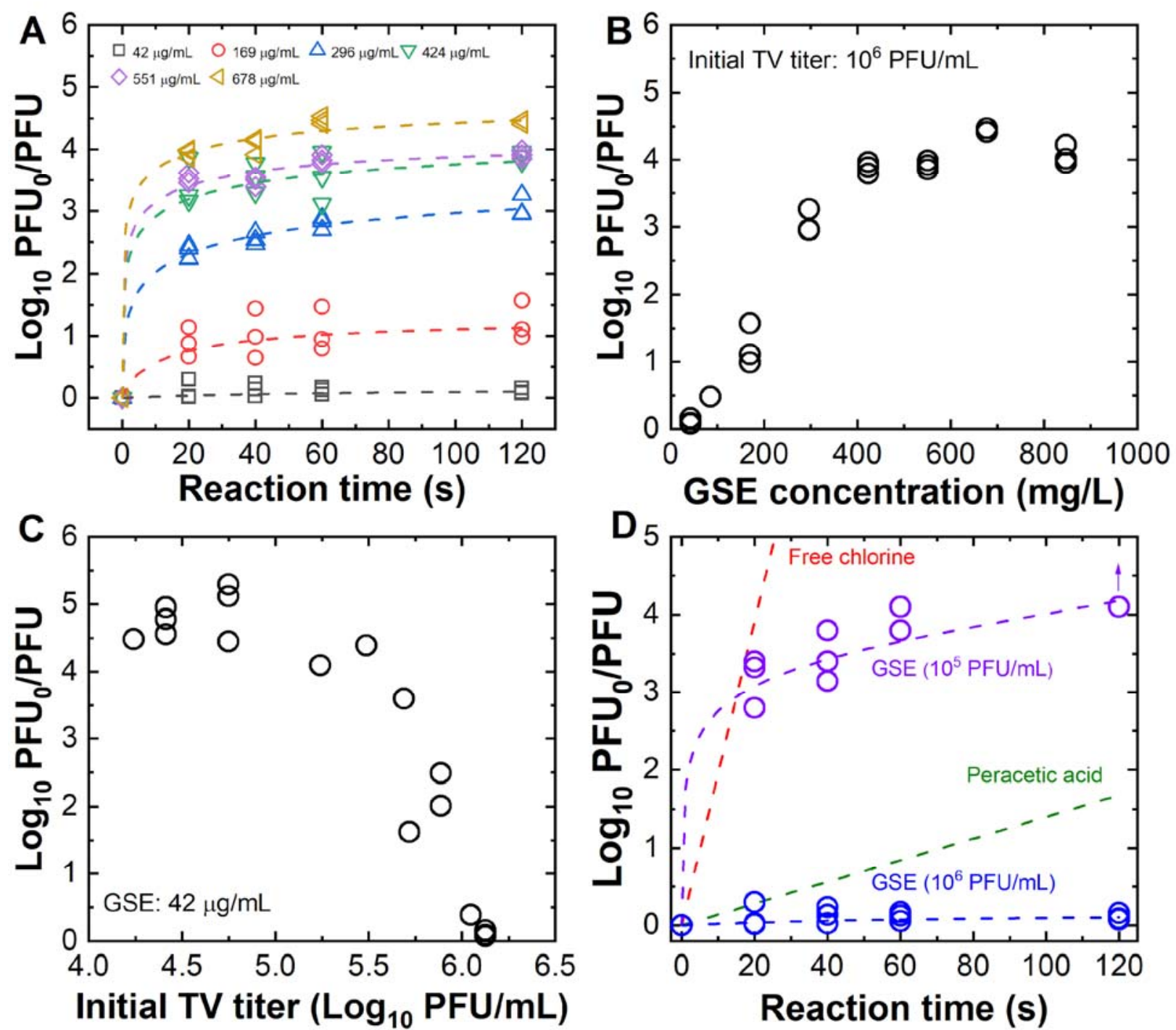

109

Fig. 1. Inactivation effects of GSE on Tulane virus. $10^{6} \mathrm{PFU}$ Tulane virus was incubated with the indicated amount of GSE. FBS was added to quench each reaction at the indicated times. Initial virus titer $\left(\mathrm{PFU}_{0}\right)$ was divided by the virus titer at each indicated time (PFU). Thus, the $y-$ axis $\left(\log _{10} \mathrm{PFU}_{0} / \mathrm{PFU}\right)$ indicates the decrease in virus titer caused by GSE on $\log _{10}$ scale. For all experiments, each symbol represents one molecular replicate. (A) The dashed lines were trend lines calculated by the pseudo-second-order model. TV inactivation as a function of GSE concentration and time. (B) TV inactivation as a function of GSE concentration. In this experiment $10^{6} \mathrm{PFU}$ TV was incubated for 120 seconds with the indicated GSE concentrations. (C) TV inactivation as a function of GSE concentration. Varying amounts of TV (indicated on the x-axis) were added to reactions containing $42 \mu \mathrm{g} / \mathrm{mL}$ GSE. All reactions were quenched with FBS after a 120 second incubation. (D) A comparison of GSE versus peracetic acid and free chlorine inactivation. $10^{5}$ or $10^{6}$ PFU TV was incubated with GSE (42 $\left.\mu \mathrm{g} / \mathrm{mL}\right)$ for $120 \mathrm{sec}$. The trend lines for GSE were determined by the pseudo-second-order model. The arrow indicates a detection limit. Trend lines for $42 \mu \mathrm{g} / \mathrm{mL}$ free chlorine or peracetic acid were derived by Chick's law with the rate constants determined by our previous studies $(7,27)$. 
TV inactivation increased when GSE concentration and duration of incubation increased

127 (Fig. 1A). The inactivation curves were fitted to both the pseudo-second-order model and

128 Chick's law. The correlation coefficients ( $\mathrm{R}^{2}$ values), which reflect the goodness of fit, obtained

129 by the pseudo-second-order model (0.99 to 1.00) were higher than those by the Chick's law (0.34

130 to 0.54$)$ except for the lowest GSE concentration $(42 \mu \mathrm{g} / \mathrm{mL})$ where no significant reduction in

131 virus titers was detected (one-way ANOVA, $\mathrm{p}>0.05$ ). Parameters from the inactivation kinetics

132 experiments are also listed in Supplementary Table 1. The fitting to the pseudo-second-order

133 model showed that it took less than 120 seconds to reach a $95 \%$ of $\log _{10}$ PFU reductions at

134 equilibrium state (i.e., $\mathrm{t}_{95}<120$ seconds) for all tested conditions except for the $42 \mu \mathrm{g} / \mathrm{mL}$ case.

135 In Fig. 1A, better fitting achieved by the pseudo-second-order model suggested that

136 chemisorption is the dominant reaction between the polyphenols and virus particles (28-30).

137 This finding suggested there were optimal GSE:virion ratios for disinfection, as supported by

138 data in Fig. 1B and 1C. Fig. 1B showed that TV inactivation increased as GSE concentrations

139 increased, with GSE efficacy reaching a plateau at $424 \mu \mathrm{g} / \mathrm{mL}$. This plateau in GSE efficacy

140 shows a maximal number of GSE binding sites on TVs because GSE disinfection could be

141 outcompeted by the addition of TV. Fig. 1C showed that GSE disinfection efficiency decreased

142 when more TVs were added to a reaction, supporting the hypothesis that chemisorption occurs

143 between GSE and TV. Interestingly, while $42 \mathrm{mg} / \mathrm{mL}$ GSE showed no disinfection activity for

$14410^{6}$ PFU TV (in Fig. 1A), it does indeed possess anti-viral properties when lower numbers of TV

145 are present, further supporting the model that GSE polyphenols associate with TV.

146 We compared GSE inactivation rates to those of two commercially available chemical

147 disinfectants (free chlorine and peracetic acid) based on Chick's law and the rate constants

148 obtained from a previous study (27) (Fig. 1D). GSE inactivated TV to a $3-\log _{10}$ virus titer 
reduction within 16 seconds, a time identical to that of inactivation by free chlorine. In contrast,

150 peracetic acid took much longer (211 seconds) to achieve the same levels of inactivation.

\section{GSE causes viral aggregation, and this is likely the main mechanism of GSE-}

Fig. 1 data showed that GSE inactivated TV, and data suggested that there was

155 chemisorption of GSE to virions. Thus, one possibility is that GSE binds directly to TV to

156 prevent virus-host interactions. Fig. 2A quantifies GSE polyphenols in the absence or presence

157 of TV as a means to examine if GSE indeed binds to TV. We incubated $847 \mu \mathrm{g} / \mathrm{mL}$ GSE with

$15810^{6} \mathrm{PFU}$ TV. The $2 \mathrm{~mL}$ mixture then subjected to ultracentrifugation to separate free versus

159 virus-bound GSE, and GSE in supernatants of samples were quantified. As shown in Fig. 2A,

160 there was a statistically significant lower GSE concentration in supernatants when TV was

161 present, implying that GSE indeed binds to TV. Next, we used a light scattering analyzer

162 (DelsaMax Pro, Beckman Coulter) to examine particle size distributions of intact TV and GSE

163 (Fig. 2B). Untreated TV showed a polydispersed multimodal size distribution with a major peak

164 at $97 \mathrm{~nm}$ and two relatively smaller peaks at 309 and $1755 \mathrm{~nm}$. A single TV virion has a diameter

165 of $40 \mathrm{~nm}(31)$, thus most of the TVs in solution were present as dimers, and some populations of

166 viruses were present as timers. Virus populations at $1755 \mathrm{~nm}$ were likely multi-virus aggregates.

167 When TV was incubated with $15 \mu \mathrm{g} / \mathrm{ml} \mathrm{GSE}$, there was a shift in the size of the TV peak at 94

$168 \mathrm{~nm}$ to approximately $300 \mathrm{~nm}$ and $1000 \mathrm{~nm}$, implying that this concentration of GSE causes

169 aggregation of TV into trimers and perhaps 10-mers. Experiments using higher concentrations of

170 GSE resulted in greater shifts in sizes, suggesting that GSE is causing TV aggregation. GSE

171 showed a strong single peak at around $1000 \mathrm{~nm}$ regardless of GSE concentrations. This peak is 
172 believed to represent insoluble polyphenols that are self-aggregated (32). When the GSE

173 solutions were filtered with $0.1 \mu \mathrm{m}$ filter, the monodispersed peak disappeared from the particle

174 size distribution.

175

$$
\text { हี }
$$
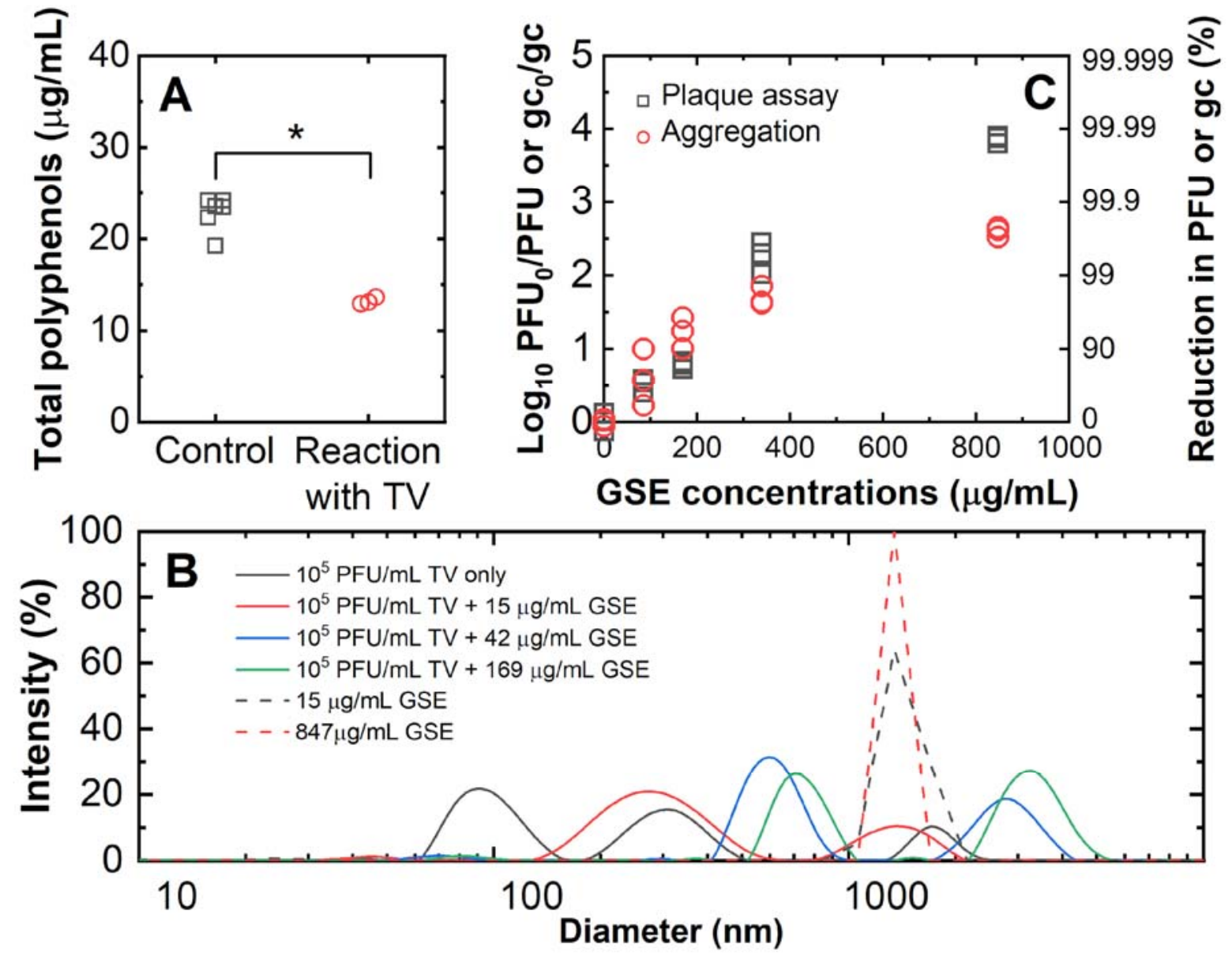

Fig. 2. GSE-induced TV aggregation. (A) Solutions either lacking (control) or containing $10^{6}$ PFU TV were each incubated with $847 \mu \mathrm{g} / \mathrm{mL}$ of GSE followed by ultracentrifugation (150700 g) for 3 hours. GSE concentrations were quantified and statistical analysis was performed using the Mann-Whitney test $(\mathrm{P}<0.05)$ (B) The particle size distribution of TV in the presence or absence of GSE. (C) A dose-response curve for plaque and aggregation assays. Plaque assay results were normalized to the initial virus titer and presented in $\log _{10} \mathrm{PFU}_{0} / \mathrm{PFU}$ to indicate the decrease in virus titer with different total polyphenol concentrations. Aggregation assay was analyzed by the one-step RT-qPCR and presented in the normalized gene copy number $\left(\log _{10}\right.$ $\mathrm{gc}_{0} / \mathrm{gc}$ ) to show the reduction in the number of virions. Equivalent reductions in PFU or $\mathrm{gc}(\%)$ were also presented on the right $y$-axis for plaque assay and aggregation assay, respectively. For these experiments, $10^{6} \mathrm{PFU}$ TV was incubated with varying concentrations of GSE for 2 minutes 
followed by quenching the reaction with FBS. Each symbol indicates one separate experiment where one plaque assay or three qPCR analyses were conducted.

To further test if GSE induces virus aggregation, virus aggregation and virus titers were quantified in parallel to compare the numbers of virus aggregates and inactivated virus particles

194 after the GSE treatment. For assays shown in Fig. 2C, $10^{6}$ PFU TV was incubated with the 195 indicated concentrations of GSE ( 85 to $847 \mu \mathrm{g} / \mathrm{mL}$ ) for 2 minutes followed by quenching the 196 reaction with FBS. Viruses were then either quantified by plaque assay or tested using an 197 aggregation assay. Aggregation assays were designed as follows: untreated or GSE-treated TV 198 were subjected to filtration using a $0.1 \mu \mathrm{m}$ sized pore filter. Because a single TV virion has a 199 diameter of $40 \mathrm{~nm}$ (31), we expect that single and dimeric TV would easily filter through the 200 pore while virus aggregates with three or more virions would be trapped in the filter. Note that 201 our aggregation assay cannot determine a specific number of virions in virus aggregates that can 202 pass through the filter. Viruses that passed through the filter were quantified by one-step RT203 qPCR. The ratio of genome copies for untreated versus treated viruses $\left(\log _{10} \mathrm{gc}_{0} / \mathrm{gc}\right)$ were 204 plotted on the y-axis in Fig. 2C. Similar to Fig. 1, plaque assays measured virus titers in 205 untreated samples $\left(\mathrm{PFU}_{0}\right)$ versus GSE-treated samples (PFU), and data are presented as the ratio 206 of virus titers before and after exposure to GSE ( $\left.\log _{10} \mathrm{PFU}_{0} / \mathrm{PFU}\right)$ on the y-axis in Fig. 2C. 207 Virus aggregates and plaque were very similar when GSE concentrations below $400 \mathrm{ng} / \mathrm{ml}$ were 208 used. However, virus aggregates were significantly lower than inactivated virus titers when 847 $209 \mu \mathrm{g} / \mathrm{mL}$ GSE was present. This discrepancy shows the number of virus particles that are larger 210 than $0.1 \mu \mathrm{m}$ does not fully explain the number of inactivated virus particles determined by the 211 plaque assay. Nevertheless, paired t-test revealed that there was no significant difference 
212 between the plaque assay and aggregation assay results over the different GSE concentrations

213 ( $\mathrm{P}>0.05)$. Thus, our current model is that GSE interacts with TV capsid, causing TV aggregation.

214 In turn, aggregation would likely prevent TV from entering host cells. We also demonstrate that

215 GSE aggregation was not reversible; removal of GSE from TV-containing solutions did not

216 make aggregated TV return back into single particle solutions (Supplementary Text 1).

218 Molecular docking indicated polyphenols strongly bound to capsid proteins

219 Data from Fig. 2 indicated that GSE is physically associated with TV and induced virus 220 aggregation, and that this event likely prevents TV from entering the host cell to begin the virus

221 life cycle. To further investigate this possibility, we conducted molecular docking simulations,

222 an approach that was used to identify interactions between polyphenolic compounds and proteins

223 (33, 34). GSE is a mixture of various polyphenolic compounds $(35,36)$. We selected nine

224 polyphenolic compounds present in GSE for molecular docking experiments. We chose these 225 compounds based on abundance (36), and this included two phenolic acids (gallic acid and

226 protocatechuic acid), three monomer flavan-3-ols (catechin, epicatechin, and epicatechin

227 gallate), and four dimer flavan-3-ols based on LC-MS analysis (procyanidin B1, B2, B3, and B4)

228 (Supplementary Table 2). Although we conducted inactivation experiments using TV, we could

229 not perform molecular docking simulations with the TV capsid because there is no entry for the

230 TV capsid in the Protein Data Bank (PDB, https://www.rcsb.org/). Cryo-EM analysis has shown

231 similarity between the TV and human norovirus (HuNoV) capsids (31), and the HuNoV capsid

232 structure is present in the PBD. Thus, we studied the interaction of the GSE polyphenols with the

233 HuNoV VP1 capsid proteins to understand how GSE may interact with similar TV capsid 234 proteins. 
We performed flexible molecular docking simulations $(37,38)$ between each of the nine

236 GSE polyphenolic compounds and HuNoV VP1 proteins to discern stable docking

237 conformations, across the four domains of VP1 (S, S-P1 hinge, P1, and P2 domain;

238 Supplementary Fig. 2) to identify where each of the polyphenols tended to bind in order of

239 domain preference. For these simulations, we used the HuNoV icosahedral asymmetric unit

240 (PDB ID: 1IHM) that comprised three VP1 proteins because the complete HuNoV capsid

241 consists of 180 identical icosahedral asymmetric units. Residue-level domain definitions have

242 been described by Campillay-Véliz et al. (39). Flexible molecular docking simulations are shown

243 in Fig. 3. The expected binding strength of each polyphenol (in increasing order of

244 size/molecular weight) with $\mathrm{HuNoV}$ capsid protein has been reported where the error bars

245 indicate variance across top 15 polyphenol binding poses within the same capsid groove. The

246 scale on the right indicates fractional capsid-binding affinity of a given polyphenol with respect

247 to the positive control - BSA. Larger polyphenols tend to show increased affinity towards both

248 the positive control and target capsid of $\mathrm{HuNoV}$. Analysis of binding affinities from docking

249 experiments reveal greater electrostatic stabilization of the larger conjugated electron systems

250 within the bigger polyphenols by the polar grooves of HuNoV capsid and bovine serum albumin

251 alike. Data demonstrated that each of the nine polyphenolic compounds examined from GSE

252 likely bound to different residues or regions of the $\mathrm{HuNoV}$ capsid protein. In addition, these

253 polyphenols appeared to bind to a location at the dimeric interface of the trimeric capsid protein.

254 The scores obtained from the simulation reflect the enthalpic contribution of binding $(\mathrm{kcal} / \mathrm{mol})$

255 between the polyphenols and the capsid (40). Fifteen independent trajectories of docking were

256 performed using the docking protocol from OptMAVEn-2.0 suite (38) and the Rosetta energy

257 function (41) was used to score the docked poses. The expected binding score was reported to be 
258 the modal value (i.e., most probable score) across the fifteen recorded values per complex. Since

259 the polyphenols tend to show a conjugated electron system, larger polyphenols showed better

260 electrostatic stabilization by the polar binding groove offered by the capsid proteins.

261 Consequently, flavan-3-ol dimers showed stronger binding affinities to the capsid protein than

262 smaller groups of polyphenols (Fig. 3). The polyphenol-capsid interaction profiles were

263 composed primarily of hydrogen bonds along with hydrophobic interactions, accounting for the

264 efficient capsid capture seen in experiments (Fig. 4). For example, the smallest polyphenol

265 protocatechuate establishes three hydrogen bonded and three hydrophobic contacts while

266 procyanidin (the largest polyphenolic compound) shows up to ten hydrogen bonded contacts yet

267 maintaining the same number of hydrophobic interactions with the capsid (Supplementary Fig.

268 3). In addition to being concordant with a previous experimental study showing that

269 polyphenols' binding affinity to proteins (e.g., BSA and human salivary $\alpha$-amylase) increased

270 with their molecular weights (42), we also provide key biophysical insights for the same in this

271 work (Fig. 4). Binding affinities for respective polyphenols with the HuNoV capsid were near-

272 equal to that of bovine serum albumin, our positive control (Fig. 3). The bovine serum albumin

273 is known as the major protein in FBS (43), with reported quenching activity towards

274 polyphenolic compounds. Thus, our results indicated that the GSE polyphenols tend to promote

275 capture of viral capsids with high efficiency. 


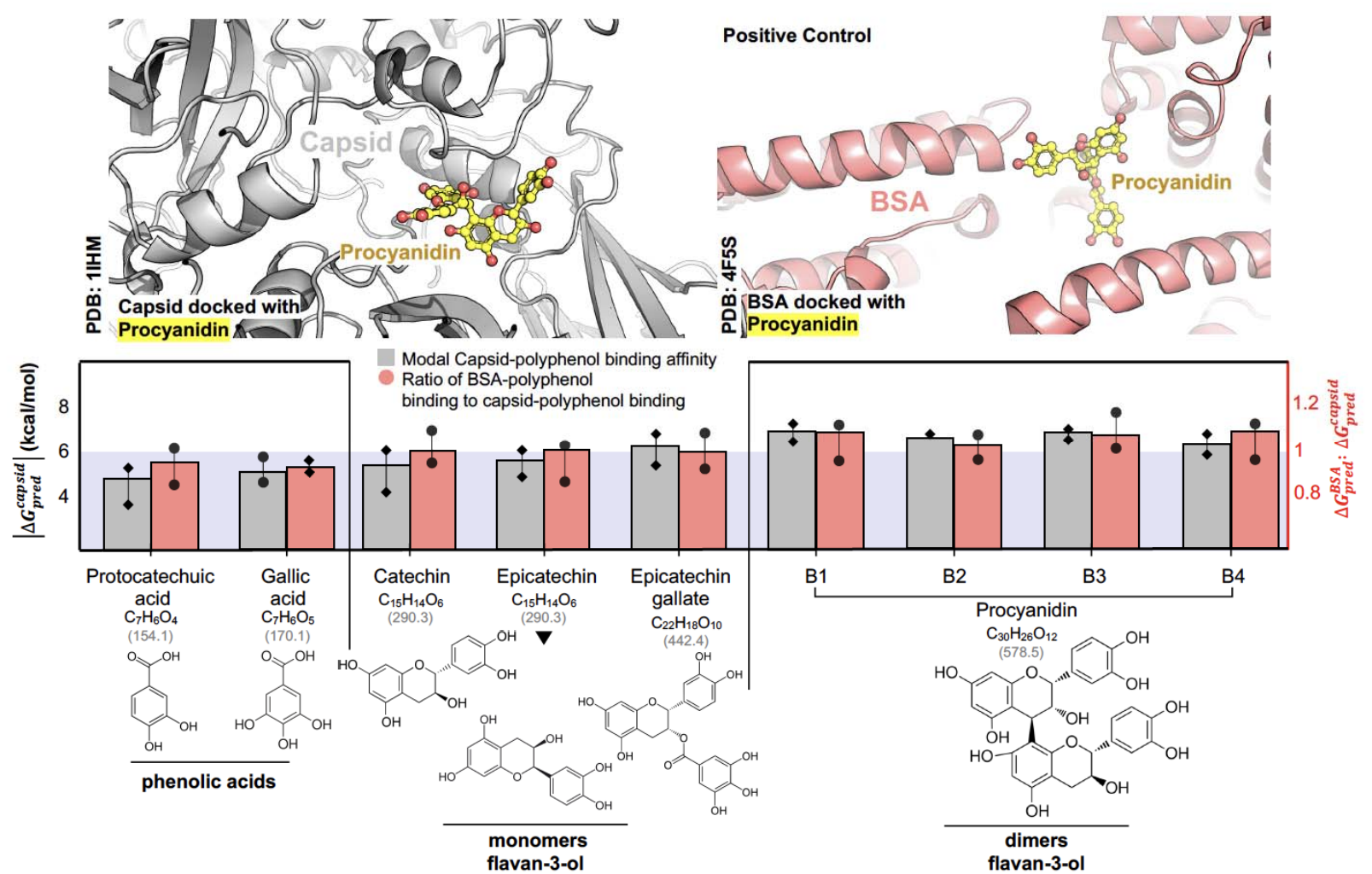

Fig. 3. Summary of molecular docking analysis between HuNoV capsid and GSE selected polyphenols found in GSE. BSA, which is known to bind strongly with polyphenols (14), was used as a positive control. The expected binding strength of each polyphenol (in increasing order of size/molecular weight) with $\mathrm{HuNoV}$ capsid protein (PDB id: 1IHM) has been reported where the error bars indicate variance across top 15 polyphenol binding poses within the same capsid groove. The scale on the right indicates fractional capsid-binding affinity of a given polyphenol with respect to the positive control - BSA. 
A

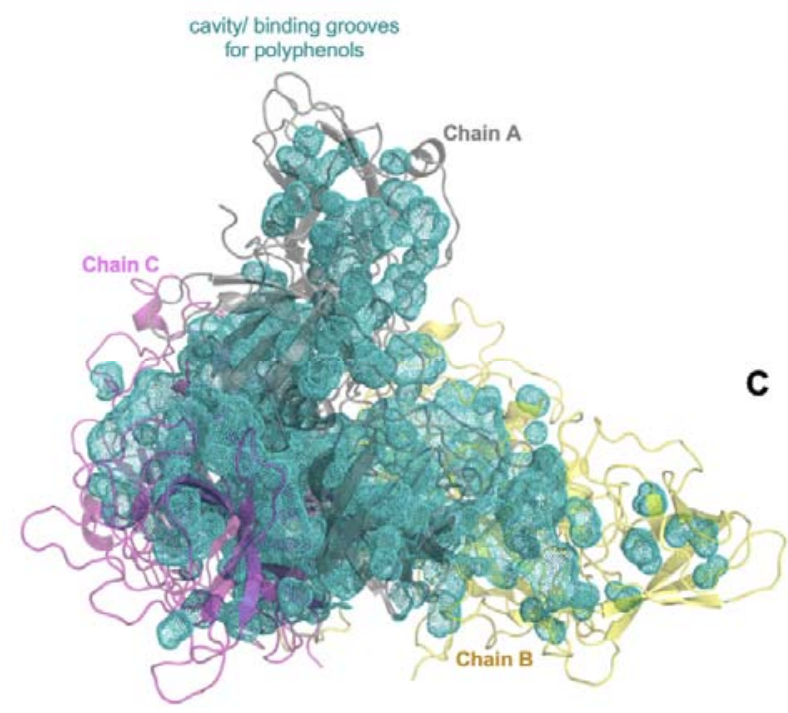

C
B

\begin{tabular}{|c|c|c|c|c|c|c|c|c|c|c|}
\hline \multicolumn{3}{|c|}{ Hydrophobic Contacts } & \multicolumn{8}{|c|}{$\mathrm{H}$-bonded interaction } \\
\hline $\begin{array}{l}\text { Res. } \\
\text { Num }\end{array}$ & $\begin{array}{l}\text { Res. } \\
\text { Name }\end{array}$ & $\begin{array}{l}\text { Distan } \\
\text { ce }(\tilde{\AA})\end{array}$ & $\begin{array}{l}\text { Res. } \\
\text { Num }\end{array}$ & $\begin{array}{l}\text { Res. } \\
\text { Name }\end{array}$ & $\begin{array}{l}\text { Distance } \\
(\bar{\AA})\end{array}$ & $\begin{array}{l}\text { Donor } \\
\text { Angle } \\
\text { (") }\end{array}$ & $\begin{array}{l}\text { Res. } \\
\text { Num }\end{array}$ & $\begin{array}{l}\text { Res. } \\
\text { Name }\end{array}$ & $\begin{array}{c}\text { Distance } \\
(\bar{\AA})\end{array}$ & $\begin{array}{l}\text { Donor } \\
\text { Angle } \\
\text { (") }\end{array}$ \\
\hline $3084 \mathrm{~B}$ & SER & 3.79 & 3084B & SER & 3.21 & 166.2 & $3174 \mathrm{~B}$ & ASP & 3.91 & 169.2 \\
\hline $3178 B$ & GLU & 3.43 & 3088B & HIS & 3.52 & 129.3 & 3175B & ARG & 3.63 & 113.4 \\
\hline \multirow[t]{3}{*}{$3506 \mathrm{~B}$} & TRP & 4.81 & 3103B & TRP & 3.92 & 139.4 & 3453B & VAL & 3.67 & 161.4 \\
\hline & & & 3133B & GLY & 2.96 & 117.5 & $3455 \mathrm{~B}$ & GLU & 4.01 & 125.4 \\
\hline & & & $3134 \mathrm{~B}$ & SER & 3.21 & 143.0 & $3508 \mathrm{~B}$ & SER & 3.77 & 133.7 \\
\hline
\end{tabular}

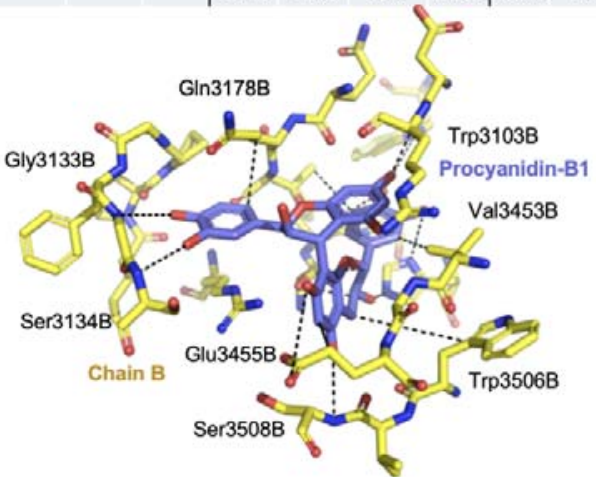

Fig. 4. Larger polyphenols show greater electrostatic stabilization with the viral capsid. (A) HuNoV capsid shows a trigonal-symmetric polyphenol accessible groove (indicated in teal), which includes three intra-chain pockets, and three inter-chain binding crevices. Smaller polyphenols can access the inter-chain crevices, while the bigger ones remain localized to the more solvent-exposed intra-chain pockets. (B) Residue level interactions of Procyanidin-B1 with the HuNoV capsid are listed. (C) A graphical overview of the exact docked pose of Procyanidin$\mathrm{B} 1$ in the capsid groove with most of the interactions is illustrated.

It is noteworthy that as the size of the polyphenol increases, it tends to bind to a lessburied, more solvent exposed pocket (owing to steric clashes) (Fig. 5) yet binding to the interface of two chains of the trimeric capsid (located around the S-P1 hinge domain; Supplementary Fig. 2). Only the largest Procyanidin (B1-B4) polyphenols cannot access the inter-chain interface pockets and are primarily surface binders with most interactions limited to a single chain (Fig. 5). We thereby hypothesize that larger polyphenols tend to be surface binders but stronger capsid binders, while smaller ones preferably bind to inter-chain interfaces of the viral capsid. In terms of domains bound, our docking simulations, in concordance with the experimental data, show that most polyphenols bind to the S or S-P1 hinge domains - while trace binding is observed in the P1 domain and P2 domain is mostly unbound. 


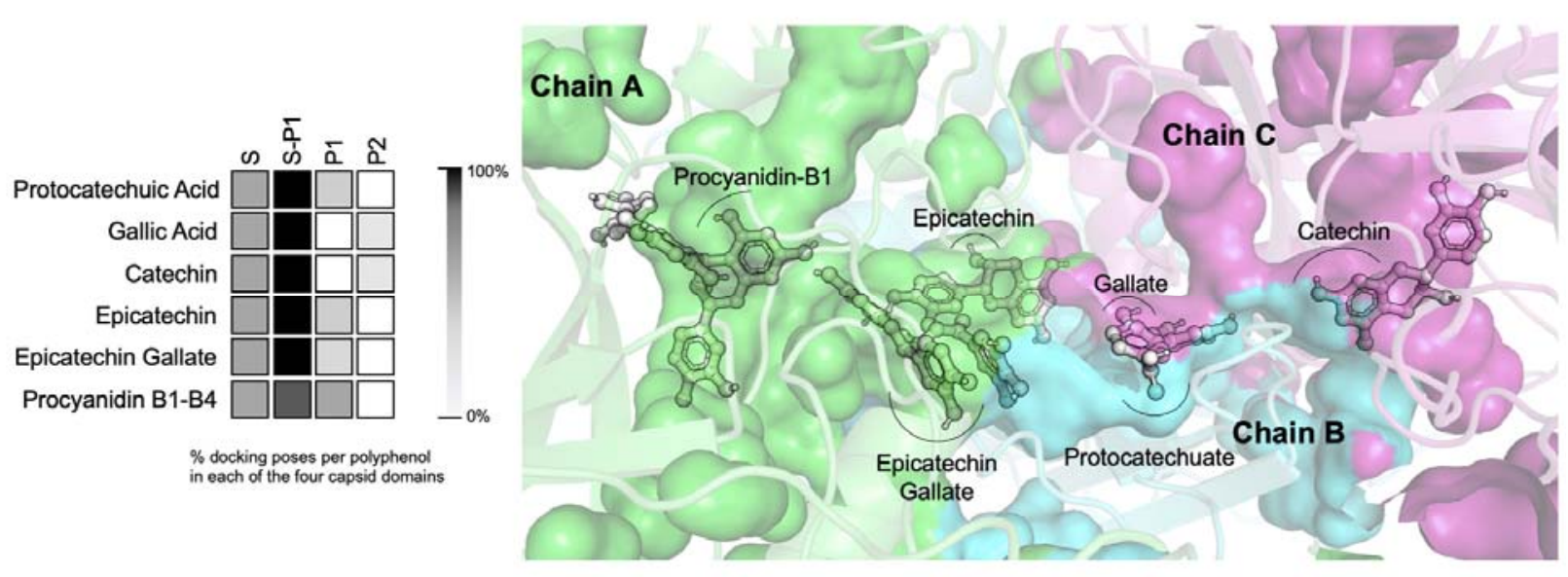

Fig. 5. All polyphenol binding is primarily localized around the S and S-P1 hinge domains of the HuNoV capsid - while the P2 domain remains mostly unbound. Smaller polyphenols can access more buried inter-chain pockets of the HuNoV capsid, while larger Procyanidins bind to surfaceexposed pockets with a single chain. Pockets guarded by each chain have been indicated by a different color (green - A, cyan - B, magenta - C). Smaller polyphenols - protocatechuate, gallate, and catechin bind best at the interface of chains B and C. Slightly larger epicatechin and epicatechin gallate bind best at the interface of chain A and B, while larger procyanidins (all B1 through B4) bind best to a solvent-exposed cavity within chain A only.

We extended the molecular docking simulations to other enteric viruses such as feline calicivirus (FCV-F9), murine norovirus (MNV-1), and hepatitis A virus (HAV) that were experimentally studied in previous works $(14,18,19)$. Although the three sets of experiments were performed in different conditions such as different virus media (water or produce) and different $\mathrm{pH}$, they presented a similar trend that FCV-F9 is more susceptible to the polyphenols in GSE than MNV-1 and HAV. Our molecular docking simulation agreed with the experimental data with these enteric viruses. The binding energy of the polyphenols to FCV-F9 capsid protein were stronger than those of MNV-1 and HAV (P<0.05) (Fig. 6). Note that the binding energy alone will not be sufficient information to evaluate the antiviral effect of the polyphenols because 


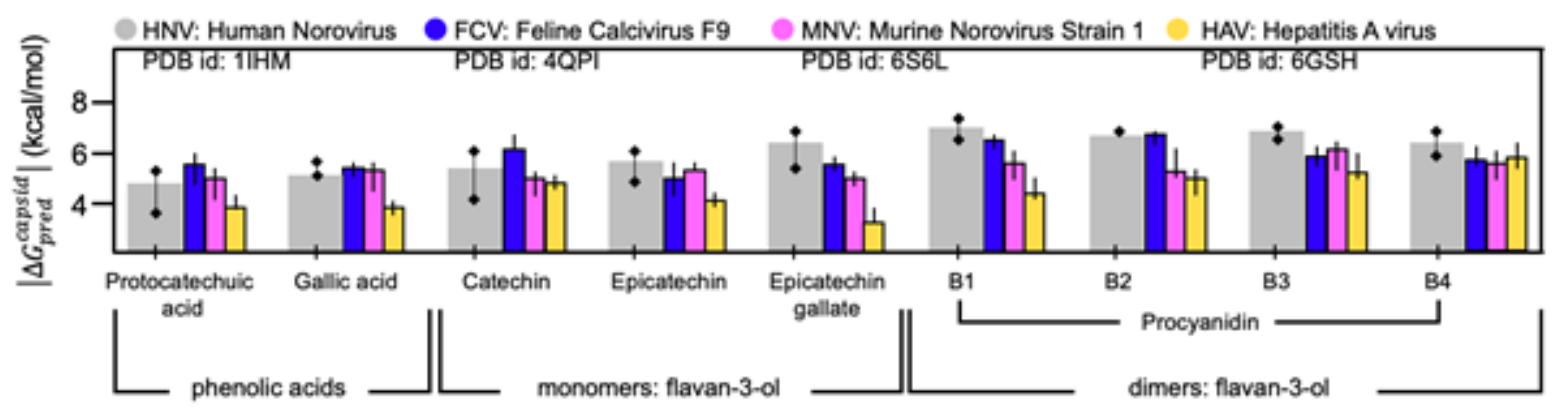

Fig. 6. Expected binding energies (absolute modal values) between each polyphenolic compound and the four viral capsids (HuNoV: human norovirus, FCV: feline calicivirus F9, MNV: murine norovirus strain 1, and HAV: hepatitis A virus) were computed using the Rosetta binding energy function from top 15 docking poses per complex. The error bars indicate variance from the 15 docked poses for each complex. The reported energy scores were compared by a paired sample ttest indicating a statistically significant higher polyphenol binding activity by HuNoV and FCV in contrast to MNV $(\mathrm{P}<0.05)$ and HAV $(\mathrm{p}<0.001)$ capsids.

\section{Discussion}

Anti-bacterial, anti-biofilm, and anti-fungal effects of plant-derived polyphenols are well-

$341 \mathrm{TV}$, a surrogate virus for $\mathrm{HuNoV}$, and the antiviral mechanisms. Data shown here suggest that

342 GSE can inactivate TV and perhaps other enteric viruses. In addition, data show that the

343 polyphenols in GSE aggregate the virus particles, an event that is likely responsible for TV

344 inactivation. Indeed, this concept that TV adsorbs polyphenols was also supported by the binding

345 energy calculated by molecular docking analysis. Our current model is that TV aggregation

346 prevents proper virus-host interactions or virus entry into host cells. There is at least one other

347 report of aggregation of herpes simplex virus, prevents virus entry into cells while allowing virus 348 attachment (44). 
It should be noted that the TV concentrations used in this study are likely much higher

350 than that found in contaminated produce or water. For example, rotavirus concentration in river

351 water, treated wastewater, and untreated wastewater are reported to be $10^{-3.0}, 10^{-2.2}$, and $10^{-1.3}$

352 FFU/mL respectively $(45,46)$. Given that GSE was efficacious using these artificially high TV

353 concentrations used in the laboratory, it is reasonable to expect that GSE would be effective as

354 an anti-viral for contaminated food or produce. Also, Tulane virus is more resistant to chemical

355 disinfectants than the other viruses in the Caliciviridae family (47). Thus, if GSE were an

356 effective disinfectant of Tulane virus then it is likely GSE would be efficacious against other

357 caliciviruses, and this is an avenue of future research. GSE is also attractive because it is safe for

358 consumption by humans. Thus, GSE or plant-derived polyphenols could be advantageous over

359 the chemical disinfectants for direct addition to end-products that people ingest such as drinking

360 water and foods.

361 There are still several important questions to answer before polyphenols can be widely

362 used to inactivate the water-borne and food-borne pathogens. Water contains other organic

363 matter which could outcompete viruses for binding to polyphenolic compounds. For example,

364 Joshi et al. (14) showed the antiviral efficacy decreased when milk (which has high proteins) was

365 added to an inactivation reaction. Thus, further studies need to be performed to understand how

366 effective GSE is in water that has different properties. Other water properties (e.g., pH, ionic

367 strength, and temperature) are important for adsorption reactions, and additional studies need to

368 address how these properties may affect the efficacy of GSE. If GSE or individual polyphenols

369 were to be used for foods (e.g., apples) then we must also understand how the surface properties

370 of foods (e.g., wax contents of produce surface) may affect the efficacy of GSE (27). 


\section{Materials and Methods}

\section{Commercially available grape seed extract and its plant-derived polyphenols}

374 We purchased a commercial grape seed extract (GSE) solution for this research (7832, Natures

375 plus, USA). The total polyphenol (TP) concentration in each GSE sample was quantified by the

376 colorimetric method using Folin-Ciocalteu reagent. A mixture of $100 \mu \mathrm{L}$ GSE sample and 500

$377 \mu \mathrm{L}$ of $10 \%$ Folin-Ciocalteu phenol reagent (Sigma-Aldrich, MO, USA) was prepared in a $10 \mathrm{~mm}$ 378 path length polymethyl methacrylate (PMMA) cuvette (BrandTech Scientific, CT, USA). Within

3793 to $8 \mathrm{~min}$ of mixture preparation, $400 \mu \mathrm{L}$ of $7.5 \%$ sodium carbonate solution was added to the 380 mixture and homogenized by pipetting. After incubating at room temperature for 60 minutes, UV 381 absorbance at $765 \mathrm{~nm}$ was measured by a spectrophotometer (UV-2450, Shimadzu, Japan).

382 Distilled water was used as a reference solution. The same procedure was conducted with gallic 383 acid solutions with different concentrations prepared by diluting gallic acid monohydrate 384 (Sigma-Aldrich, MO, USA) in distilled water. The TP concentrations of the gallic acid solutions 385 were used for a calibration curve (Supplementary Fig. 4) which determined TP concentration of 386 the GSE samples. GSE with TP concentrations ranging from 84 to $1694 \mu \mathrm{g} / \mathrm{mL}$ was prepared by 387 diluting the initial GSE with $1 \mathrm{X}$ PBS and used for inactivation experiments.

388 The polyphenol composition of GSE was analyzed by liquid chromatography-mass 389 spectrometry (Q Exactive ${ }^{\mathrm{TM}}$ Plus Hybrid Quadrupole-Orbitrap ${ }^{\mathrm{TM}}$ Mass Spectrometer, Thermo 390 scientific, USA), and numerous peaks were discovered by untargeted comprehensive metabolite 391 profiling (Supplementary Table 2). Although the LC/MS analysis could not quantify each 392 polyphenol and differentiate polyphenolic isomers with the same $\mathrm{m} / \mathrm{z}$ values, such as 393 catechin/epicatechin at 291 of $\mathrm{m} / \mathrm{z}$ ratio for $[\mathrm{M}+\mathrm{H}]^{+}$and $\mathrm{B}$ type procyanidins at $579 \mathrm{of} \mathrm{m} / \mathrm{z}$ ratio 394 for $[\mathrm{M}+\mathrm{H}]^{+}$, the major peaks agreed with the primary polyphenolic compounds in GSE that were 
395 confirmed by other studies $(35,36)$. With the mass spectrometry and the references

396 characterizing polyphenols in GSE, we chose nine target polyphenolic components, which

397 include three monomers flavan-3-ols (catechin, epicatechin, and epicatechin gallate), four dimers

398 flavan-3-ols (Procyanidin B1, Procyanidin B2, Procyanidin B3, and Procyanidin B4), and two

399 phenolic acid (gallic acid and protocatechuic acid). These nine polyphenolic compounds were

400 further studied through molecular docking simulations.

401

402

\section{Tulane virus propagation}

403

Tulane virus (TV) was used as a surrogate for human norovirus (HuNoV). Both TV and

$404 \mathrm{HuNoV}$ are members of Caliciviridae and share structural similarities. TV and HuNoV have a

405 positive-sense, single-stranded genomic RNA of $6.7 \mathrm{~kb}$ and $7.5 \mathrm{~kb}$, respectively. About 23-26\%

406 of the genome sequences are identical in both viruses (20). The capsid of TV has $\mathrm{T}=3$

407 icosahedral symmetry and is $40 \mathrm{~nm}$ in diameter. The capsid comprises 180 copies of major

408 capsid protein (VP1) or 90 dimers of A/B or C/C. The VP1 is also sub-divided into S, P1, and P2

409 domains. When the VP1 proteins are assembled, the S domains comprise the bottom surface of

410 the capsid while P1 and P2 domains protrude out of the bottom surface, which is responsible for

411 binding to receptor proteins (Supplementary Fig. 1). TV recognizes Histo-blood group antigens

412 (21) and sialic acids (22) as cellular receptors similar to HuNoVs. Besides, TV is considered

413 more resistant to disinfectants than the other viruses in Caliciviridae (47). Therefore, TV has

414 been widely used in virus inactivation experiments as a surrogate for HuNoVs (7, 23-27).

415 TV was a gift from Cincinnati Children's Hospital Medical Center (22) and the TV

416 genome was sequenced as quality control. The genome sequence was $100 \%$ identical to those of

417 a wild-type TV strain in Genbank (Access number: EU391643) (7). TV was propagated in 
418 MA104 cells, which was purchased from ATCC (CRL-2378.1), and grown in complete culture

419 medium (i.e., 1X minimum essential medium (MEM; Thermo Fisher Scientific, USA), 10\% fetal

420 bovine serum (FBS; Thermo Fisher Scientific, USA), 1X antibiotic-antimycotic (Thermo Fisher

421 Scientific, USA), $17 \mathrm{mM}$ of $\mathrm{NaHCO}_{3}, 10 \mathrm{mM}$ of HEPES, and $1 \mathrm{mM}$ of sodium pyruvate

422 (Thermo Fisher Scientific, USA). When greater than 90\% of MA014 cellular monolayers

423 showed cytopathic effects (about 2 days after the inoculation), cells were harvested and collected

424 by centrifugation, and TV was released from host cells by three cycles of freeze and thaw. Virus

425 was separated from cellular debris by centrifugation at $2000 \mathrm{rpm}$ (556 g) for 10 min (Sorvall

426 Legend RT Plus, Thermo Fisher Scientific, USA). The supernatant was treated by filtration with

427 a $0.22 \mu \mathrm{m}$ bottle top filter (Milliporesigma, USA) to remove additional cellular debris. The virus-

428 containing filtrate was then further purified using an ultracentrifuge (Optima XPN-90

429 Ultracentrifuge, Beckman Coulter, USA) with a cycle of 1,000 rpm (116 g) for 5 min followed

430 by $36,000 \mathrm{rpm}(150700 \mathrm{~g})$ at $4^{\circ} \mathrm{C}$ for 3 hours. The virus pellet was resuspended in $1 \mathrm{X}$ PBS,

431 aliquoted, and stored at $-80 \square$ before use.

\section{Tulane virus inactivation experiments using GSE}

434 Virus inactivation experiments were initiated by adding $250 \mu \mathrm{L}$ of TV solution containing 2.5

$435 \times 10^{5}$ PFU TV to $250 \mu \mathrm{L}$ of GSE-containing solution, in which GSE concentrations ranged from

43684 to $1694 \mu \mathrm{g} / \mathrm{mL}$. After the incubation times indicated in the manuscript (i.e., 10 to 120

437 seconds), $70 \mu \mathrm{L}$ of the mixture was added to $70 \mu \mathrm{L}$ of FBS to quench the polyphenolic

438 activity(14). Thus, the volumetric ratio of TV, GSE, and FBS in the final solution was 1:1:2. The

439 FBS quenching activity was confirmed in Supplementary Fig. 5. Negative controls were

440 prepared for every virus inactivation experiment. In this case, the negative controls were 
441 prepared by mixing TV, GSE, and FBS in the ratio of 1:1:2, but in a different mixing order.

442 Specifically, $35 \mu \mathrm{L}$ of GSE was mixed with $70 \mu \mathrm{L}$ of FBS to quench the polyphenolic activity

443 followed by adding $35 \mu \mathrm{L}$ of TV to the mixture (Fig. 1A). The final mixture of TV, GSE, and

444 FBS was used for further analysis.

\section{Plaque assays}

447 The MA104 cell line was grown in $175 \mathrm{~cm}^{2}$ flasks (Thermo Fisher Scientific, USA) with the 448 complete culture medium. Cells were seeded into 6-well plates (CC7682-7506, USA Scientific, 449 USA) resulting in cellular monolayers with more than $90 \%$ confluency. Cell culture supernatants

450 were aspirated using a vacuum-connected pasteur pipette. $100 \mu \mathrm{L}$ of TV samples were serially 451 diluted by 10-fold dilutions. Cellular monolayers were incubated with each of the serially-diluted 452 viruses for 1 hour at $37 \square$ with $5 \% \mathrm{CO}_{2}$ to facilitate virus attachment to the MA104 cells. Viruses 453 were aspirated from cellular monolayers and $2 \mathrm{~mL}$ of overlay solution containing 1X MEM, 1\% 454 agarose, $7.5 \%$ sodium bicarbonate, $15 \mathrm{mM}$ HEPES, and $1 \mathrm{X}$ antibiotic-antimycotic was added to 455 each well. The overlay solution was solidified at $4 \square$ for 10 minutes. Plates were incubated for 2 456 days at $37 \square$ with $5 \% \mathrm{CO}_{2}$ to allow infectious viruses to form plaques. Next, $2 \mathrm{~mL}$ of $10 \%$ 457 formaldehyde (VWR, USA) in 1X PBS was added to each well and incubated at room 458 temperature for 1 hour to fix cells. The agarose and the formaldehyde were removed and 459 replaced with a $0.05 \%$ crystal violet dye solution. The solution was washed away after 10 460 minutes and the number of plaque-forming units (PFU) was counted on a lightbox (ULB-100, 461 Scienceware). The detection limit of the plaque assay was one plaque on the least diluted sample 462 (i.e., 10-fold dilution), which was equivalent to $10^{1.1} \mathrm{PFU} / \mathrm{mL}$. 


\section{Models for virus inactivation kinetics}

465 TV inactivation kinetics were interpreted by a first-order reaction of Chick's law (Eqs. 1-3) and

466 pseudo-second-order model (Eqs. 4-6). Chick's law assumes the activity (i.e., concentration) of

467 available disinfectant remains constant during the reaction. Chick's law has been widely used to

468 describe virus inactivation kinetics by free chlorine, peracetic acid, monochloramine, heat,

469 ozone, and UV(7, 48-51).

470

471

$\frac{d N}{d t}=-k c N$

$472 \ln \frac{N}{N_{0}}=-k c t$

$473 \quad \log _{10} \frac{N_{0}}{N}=k^{\prime} c t$

474

475 Where $N$ referred to viral infectivity (PFU/mL), $c$ indicated the TP concentration $(\mu \mathrm{g} / \mathrm{mL}), t$ was

476 treatment time $(\mathrm{s}), k^{\prime}$ meant an inactivation rate constant from Chick's law $(\mathrm{L} / \mu \mathrm{g} \cdot \mathrm{s})$.

477 The pseudo-second-order model has been widely used to describe reactions where

478 chemisorption between adsorbent and adsorbate is the rate-determining step (28). In this study,

479 TV and TP were considered as adsorbate and adsorbent, respectively.

480

$481 \quad \frac{d C_{t}}{d t}=k_{2}\left(C_{e}-C_{t}\right)^{2} \quad$ (Eq. 4)

$482 \quad \frac{t}{C_{t}}=\frac{1}{C_{e}^{2} k_{2}}+\frac{1}{C_{e}} t \quad$ (Eq. 5)

$483 \quad t_{95 \%}=\frac{19}{C_{e} k_{2}} \quad$ (Eq. 6) 
485 Where $\mathrm{t}$ is the reaction time $(\mathrm{s}), \mathrm{k}_{2}$ is the rate constant from the pseudo-second-order model

$486(\mathrm{~mL} / \mathrm{PFU} \cdot \mathrm{s}), \mathrm{C}_{\mathrm{t}}$ and $\mathrm{C}_{\mathrm{e}}$ are inactivated $\mathrm{TV}$ concentration $(\mathrm{PFU} / \mathrm{mL})$ at time $\mathrm{t}$ and equilibrium

487 state, respectively. Also, $\mathrm{t}_{95 \%}$ is a reaction time at which $\mathrm{C}_{\mathrm{t}}$ reaches $95 \%$ of $\mathrm{C}_{\mathrm{e}}$.

\section{Virus particle size}

The particle size distribution of TV was measured by a light scattering analyzer

491 (DelsaMax Pro, Beckman Coulter). TV, GSE, and FBS either alone or in combination were 492 prepared in $200 \mu \mathrm{L}$ aliquots, placed in a PMMA cuvette (BrandTech Scientific, USA). Particle

493 size was measured 20 times for each sample, and the averaged \% intensity was presented with

494 the particle diameter. According to the manufacturer, particle size analysis is reliable within a

495 range from 0.4 to $10,000 \mathrm{~nm}$, and all our measurements were in this detection range.

497 Virus aggregation assay

498 An assay was developed to quantify TV virions that are less than $100 \mu \mathrm{m}$ in diameter. After the

499 TV inactivation experiments were conducted, the mixture containing viruses, GSE, and FBS was

500 filtered with a $0.1 \mu \mathrm{m}$ syringe filter (Sartorius, Germany). The number of virus particles in the

501 initial mixture and the filtrate was quantified by one-step RT-qPCR. RNA was extracted from

502 samples using Viral RNA Mini Kit (QIAGEN, Germany) in a final $60 \mu \mathrm{L}$ volume. RT-qPCR

503 samples were prepared in 96-well plates (4306737, Applied Biosystems, USA) by mixing $5 \mu \mathrm{L}$

504 of $2 \times$ iTaq universal SYBR green reaction mix, $0.125 \mu \mathrm{L}$ of iScript reverse transcriptase from

505 the iTaq universal SYBR green reaction mix (Bio-Rad Laboratories, USA), $3 \mu \mathrm{L}$ of the RNA, 0.3

$506 \mu \mathrm{L}$ of $10 \mu \mathrm{M}$ TV-NSP1-qPCR-F primer, $0.3 \mu \mathrm{L}$ of $10 \mu \mathrm{M}$ TV-NSP1-qPCR-R primer, and 1.275

$507 \mu \mathrm{L}$ of nuclease-free water. The one-step RT-qPCR was run using a qPCR system (QuantStudio 
3, Thermo Fisher Scientific, USA) with the following thermocycle: 10 minutes at $50 \square$ and 1

509 minute at $90 \square$ followed by 40 cycles of 30 seconds at $60 \square$ and 1 minute at $90 \square$. Detailed

510 information for primers and synthetic DNA controls is summarized in Supplementary Table 3.

511 We obtained a calibration curve by plotting the viral infectivity $\left(\log _{10} \mathrm{PFU} / \mathrm{mL}\right)$ on the $\mathrm{x}$-axis

512 and the outcome of the one step RT-qPCR assay $\left(\log _{10} \mathrm{gc} / \mathrm{mL}\right)$ on the $y$-axis for the same viral

513 solution (Supplementary Fig. 6). The calibration curve was used to determine the reliable range

514 of the binding assay. The calibration curve for the binding assay was linear (a slope=0.95 and

$515 \mathrm{R}^{2}=1.00$ ) between $10^{3}$ and $10^{7} \mathrm{PFU} / \mathrm{mL}$. The PCR standard curves were obtained with 10 -fold

516 serial dilutions of the synthetic DNA oligonucleotide (Integrated DNA technologies, USA) and

517 the PCR efficiency for this one-step RT-qPCR ranged from 85 to $95 \%\left(\mathrm{R}^{2}>0.99\right)$. Inhibitory

518 effect of GSE was also tested (Supplementary Fig. 7). We found 100-fold dilution can reduce

519 the inhibitory effect of GSE to an insignificant level, so the samples were diluted in molecular

520 grade water by 100 -fold before the RT-qPCR analysis. Information for RT-qPCR was

521 summarized following the MIQE guidelines (52) in Supplementary Table 4.

\section{Molecular docking simulation for polyphenols and capsid proteins interaction}

525 We selected nine polyphenolic compounds that are present in GSE, including two

526 phenolic acids, three monomer flavan-3-ols, and four dimer flavan-3-ols (36). The structural

527 information on the polyphenols were obtained from PUBChem

528 (https://pubchem.ncbi.nlm.nih.gov/). Although we conducted inactivation experiments with

529 Tulane virus, we obtained HuNoV capsid protein instead of TV from the Protein Data Bank

530 (PDB, https://www.rcsb.org/) to study interactions with the polyphenols because the database of 
531 PDB does not provide TV capsid information. Cryo-EM structure analysis showed that the TV

532 capsid structure closely resembles that of $\operatorname{HuNoV}(31)$.

533 We downloaded the HuNoV icosahedral asymmetric unit (PDB ID: 1IHM) which is a

534 basic building block for the HuNoV capsid. This icosahedral unit comprised three VP1 proteins

535 (i.e., chain A, B, and C in PDB format). The complete HuNoV capsid consists of 180 identical

536 icosahedral asymmetric units. We also used a deep-learning-based structure prediction tool -

537 trRosetta(53), to predict the 3D-structure of the TV capsid (Supplementary File 1) from its

538 sequence and a multiple-sequence alignment of related sequences. We studied molecular docking

539 of the polyphenols to $\mathrm{HuNoV}$ and to other different enteric viruses including hepatitis A virus

540 (PDB: 4QPI), murine norovirus-1 (PDB: 6S6L), and feline calicivirus-F9 (PDB: 6GSH). Bovine

541 serum albumin (BSA) is a major component for FBS, and BSA showed a strong binding affinity

542 to the polyphenols as confirmed by the quenching effect in the virus inactivation experiments.

543 BSA (PDB: 4F5S) was used as a positive control for molecular docking with the polyphenolic

544 compounds. Next, we used the target proteins (capsids or BSA) and flexible conformations of all

545 the aforementioned nine polyphenol ligands to discern stable docking conformations, record

546 binding affinity scores, and report across four capsid domains where each of the polyphenols

547 tend to bind in order of domain preference. The flexible docking protocol is similar to the Z-

548 Dock protocol(37) as implemented within OptMAVEn-2.0(38).

$550 \quad$ Statistical analysis

551 All experiments were repeated three times with distinct virus samples (i.e., three biological

552 replications), each of which was analyzed by three separate RT-qPCR measurements (i.e., three

553 technical replications). Paired sample t-test was used to compare results of plaque assay and 
554 aggregation assay in Fig. 2C and binding energies of different viral species (HuNoV, FCV,

$555 \mathrm{MNV}$, and HAV) to polyphenolic compounds in Fig. 6. We confirmed that all data for statistical

556 analysis satisfied assumptions of paired sample t-test (i.e., no outliers and normality). For

557 example, all data for statistical analysis were between Q1-1.5IQR and Q3+1.5IQR range, which

558 means there were no outliers. Also, differences between two data sets (e.g., plaque assay versus

559 aggregation assay in Fig. 2C or $\mathrm{HuNoV}$ versus $\mathrm{MNV}$ or HAV in Fig. 6) were normally

560 distributed $(\mathrm{P}>0.05)$.

561

\section{Acknowledgement}

563 This study was funded by National Science Foundation (Award Number: 2023248). We thank

564 Dr. Zhong (Lucas) Li at Metabolomics Lab, Roy J. Carver Biotechnology Center, University of

565 Illinois at Urbana-Champaign for characterizing polyphenolic compounds in grape seed extract. 


\section{References}

568 1. Ahmed SM, Hall AJ, Robinson AE, Verhoef L, Premkumar P, Parashar UD, Koopmans

569 M, Lopman BA. 2014. Global prevalence of norovirus in cases of gastroenteritis: A

$570 \quad$ systematic review and meta-analysis. Lancet Infect Dis 14:725-730.

571 2. Scallan E, Hoekstra RM, Angulo FJ, Tauxe R V., Widdowson MA, Roy SL, Jones JL, Griffin PM. 2011. Foodborne illness acquired in the United States-Major pathogens. Emerg Infect Dis 17:7-15.

574 3. Burke RM, Mattison CP, Pindyck T, Dahl RM, Rudd J, Bi D, Curns AT, Parashar U, Hall https://doi.org/10.1093/cid/ciaa438.

4. BITLER EJ, MATTHEWS JE, DICKEY BW, EISENBERG JNS, LEON JS. 2013. and vehicles. Epidemiol Infect 141:1563-1571.

581 5. Fraisse A, Temmam S, Deboosere N, Guillier L, Delobel A, Maris P, Vialette M, Morin

582 T, Perelle S. 2011. Comparison of chlorine and peroxyacetic-based disinfectant to

583 inactivate Feline calicivirus, Murine norovirus and Hepatitis A virus on lettuce. Int J Food $584 \quad$ Microbiol 151:98-104.

585 6. GIRARD M, NGAZOA S, MATTISON K, JEAN J. 2010. Attachment of Noroviruses to 586 Stainless Steel and Their Inactivation, Using Household Disinfectants. J Food Prot $587 \quad 73: 400-404$.

588 7. Fuzawa M, Araud E, Li J, Shisler JL, Nguyen TH. 2019. Free Chlorine Disinfection 589 Mechanisms of Rotaviruses and Human Norovirus Surrogate Tulane Virus Attached to 
Fresh Produce Surfaces. Environ Sci Technol 53:11999-12006.

591 8. Chen X, Hung YC. 2016. Predicting chlorine demand of fresh and fresh-cut produce based 592 on produce wash water properties. Postharvest Biol Technol 120:10-15.

593 9. Parish ME, Beuchat LR, Suslow T V., Harris LJ, Garrett EH, Farber JN, Busta FF. 2003.

594 Methods to reduce/ eliminate pathogens from fresh and fresh-cut produce. Compr Rev

$595 \quad$ Food Sci Food Saf 2:161-173.

596 10. Soto Beltran M, Jimenez Edeza M, Viera C, Martinez CI, Chaidez C. 2013. Sanitizing

597 alternatives for Escherichia coli and Salmonella typhimurium on bell peppers at household

$598 \quad$ kitchens. Int J Environ Health Res 23:331-341.

599 11. Matulonga B, Rava M, Siroux V, Bernard A, Dumas O, Pin I, Zock JP, Nadif R, Leynaert

600 B, Le Moual N. 2016. Women using bleach for home cleaning are at increased risk of

$601 \quad$ non-allergic asthma. Respir Med 117:264-271.

602 12. Cleveland J, Montville TJ, Nes IF, Chikindas ML. 2001. Bacteriocins: Safe, natural 603 antimicrobials for food preservation. Int J Food Microbiol. Elsevier.

604 13. Devlieghere F, Vermeiren L, Debevere J. 2004. New preservation technologies:

605 Possibilities and limitations, p. 273-285. In International Dairy Journal. Elsevier.

606 14. Joshi SS, Su X, D’Souza DH. 2015. Antiviral effects of grape seed extract against feline

607 calicivirus, murine norovirus, and hepatitis A virus in model food systems and under 608 gastric conditions. Food Microbiol 52:1-10.

609 15. Market analysis report. 2019. Polyphenols Market Size, Share \& Trends Analysis Report 610 By Product (Grape Seed, Green Tea, Cocoa), By Application (Beverages, Food, Feed, 611 Dietary Supplements, Cosmetics), And Segment Forecasts, 2019 - 2025.

612 16. Memar MY, Adibkia K, Farajnia S, Kafil HS, Yekani M, Alizadeh N, Ghotaslou R. 2019. 
613 The grape seed extract: A natural antimicrobial agent against different pathogens. Rev

$614 \quad$ Med Microbiol 30:173-182.

615 17. D’Souza DH. 2014. Phytocompounds for the control of human enteric viruses. Curr Opin $616 \quad$ Virol 4:44-49.

617 18. Su X, D’Souza DH. 2011. Grape seed extract for control of human enteric viruses. Appl $618 \quad$ Environ Microbiol 77:3982-3987.

619 19. Su X, D'Souza DH. 2013. Grape seed extract for foodborne virus reduction on produce. $620 \quad$ Food Microbiol 34:1-6.

621 20. Farkas T, Sestak K, Wei C, Jiang X. 2008. Characterization of a Rhesus Monkey 622 Calicivirus Representing a New Genus of Caliciviridae. J Virol 82:5408-5416.

623 21. Zhang D, Huang P, Zou L, Lowary TL, Tan M, Jiang X. 2015. Tulane Virus Recognizes the A Type 3 and B Histo-Blood Group Antigens. J Virol 89:1419-1427.

625 22. Tan M, Wei C, Huang P, Fan Q, Quigley C, Xia M, Fang H, Zhang X, Zhong W, Klassen JS, Jiang X. 2015. Tulane virus recognizes sialic acids as cellular receptors. Sci Rep 5:114.

628 23. Bridges DF, Breard A, Lacombe A, Valentine DC, Tadepalli S, Wu VCH. 2017. Inhibition of Tulane Virus replication via exposure to lowbush blueberry (Vaccinium 630 angustifolium) fractional components. J Berry Res 7:281-289.

631 24. Li X, Huang R, Chen H. 2017. Evaluation of Assays to Quantify Infectious Human 632 Norovirus for Heat and High-Pressure Inactivation Studies Using Tulane Virus. Food $633 \quad$ Environ Virol 9:314-325.

634 25. Ailavadi S, Davidson PM, Morgan MT, D’Souza DH. 2019. Thermal Inactivation 635 Kinetics of Tulane Virus in Cell-Culture Medium and Spinach. J Food Sci 84:557-563. 
636 26. Araud E, Fuzawa M, Shisler JL, Li J, Nguyen TH. 2020. UV inactivation of rotavirus and

637 tulane virus targets different components of the virions. Appl Environ Microbiol 86:1-12.

638 27. Fuzawa M, Bai H, Shisler JL, Nguyen TH. 2020. The basis of peracetic acid (PAA)

639 inactivation mechanisms for rotavirus and Tulane virus under conditions relevant for

$640 \quad$ vegetable sanitation. Appl Environ Microbiol 1-47.

641 28. Ho YS, McKay G. 1999. Pseudo-second order model for sorption processes. Process $642 \quad$ Biochem 34:451-465.

643 29. Ho YS, Ng JCY, McKay G. 2001. Removal of lead(II) from effluents by sorption on peat 644 using second-order kinetics. Sep Sci Technol 36:241-261.

645 30. Ho YS, Ofomaja AE. 2006. Pseudo-second-order model for lead ion sorption from 646 aqueous solutions onto palm kernel fiber. J Hazard Mater 129:137-142.

647 31. Yu G, Zhang D, Guo F, Tan M, Jiang X, Jiang W. 2013. Cryo-EM Structure of a Novel $648 \quad$ Calicivirus, Tulane Virus. PLoS One 8:59817.

649 32. Pianet I, André Y, Ducasse M-A, Tarascou I, Lartigue J-C, Pinaud N, Fouquet E, Dufourc

650 EJ, Laguerre M. 2008. Modeling Procyanidin Self-Association Processes and

651 Understanding Their Micellar Organization: A Study by Diffusion NMR and Molecular

652 Mechanics. Langmuir 24:11027-11035.

653 33. Islam B, Sharma C, Adem A, Aburawi E, Ojha S. 2015. Insight into the mechanism of 654 polyphenols on the activity of HMGR by molecular docking. Drug Des Devel Ther $6559: 4943-4951$.

656 34. Srinivasan E, Rajasekaran R. 2016. Computational investigation of curcumin, a natural 657 polyphenol that inhibits the destabilization and the aggregation of human SOD1 mutant 658 (Ala4Val). RSC Adv 6:102744-102753. 
659 35. Chedea VS, Echim C, Braicu C, Andjelkovic M, Verhe R, Socaciu C. 2011. Composition in polyphenols and stability of the aqueous grape seed extract from the romanian variety “merlot recas.” J Food Biochem 35:92-108.

36. Rodríguez Montealegre R, Romero Peces R, Chacón Vozmediano JL, Martínez Gascueña J, García Romero E. 2006. Phenolic compounds in skins and seeds of ten grape Vitis vinifera varieties grown in a warm climate. J Food Compos Anal 19:687-693.

37. Pierce BG, Hourai Y, Weng Z. 2011. Accelerating protein docking in ZDOCK using an advanced 3D convolution library. PLoS One 6.

667 38. Chowdhury R, Allan MF, Maranas CD. 2018. OptMAVEn-2.0: De novo Design of Variable Antibody Regions Against Targeted Antigen Epitopes. Antibodies 7:23.

669 39. Campillay-Véliz CP, Carvajal JJ, Avellaneda AM, Escobar D, Covián C, Kalergis AM, Lay MK. 2020. Human Norovirus Proteins: Implications in the Replicative Cycle,

40. Cosconati S, Forli S, Perryman AL, Harris R, Goodsell DS, Olson AJ. 2010. Virtual screening with AutoDock: Theory and practice. Expert Opin Drug Discov. NIH Public Access.

675 41. Chaudhury S, Lyskov S, Gray JJ. 2010. PyRosetta: A script-based interface for implementing molecular modeling algorithms using Rosetta. Bioinformatics. Oxford

678 42. Soares S, Mateus N, De Freitas V. 2007. Interaction of different polyphenols with Bovine Serum Albumin (BSA) and Human Salivary $\alpha$-Amylase (HSA) by fluorescence quenching. J Agric Food Chem 55:6726-6735.

681 43. Johnson M. 2012. Fetal Bovine Serum. Mater Methods 2. 
682 44. Bultmann H, Busse JS, Brandt CR. 2001. Modified FGF4 Signal Peptide Inhibits Entry of 683 Herpes Simplex Virus Type 1. J Virol 75:2634-2645.

684 45. Lodder WJ, De Roda Husman AM. 2005. Presence of noroviruses and other enteric 685 viruses in sewage and surface waters in The Netherlands. Appl Environ Microbiol $71: 1453-1461$.

687 46. Rutjes SA, Lodder WJ, Van Leeuwen AD, De Roda Husman AM. 2009. Detection of infectious rotavirus in naturally contaminated source waters for drinking water production. J Appl Microbiol 107:97-105.

690 47. Cromeans T, Park GW, Costantini V, Lee D, Wang Q, Farkas T, Lee A, Vinjé J. 2014. Comprehensive comparison of cultivable norovirus surrogates in response to different inactivation and disinfection treatments. Appl Environ Microbiol 80:5743-5751.

693 48. Dunkin N, Weng S, Schwab KJ, McQuarrie J, Bell K, Jacangelo JG. 2017. Comparative Inactivation of Murine Norovirus and MS2 Bacteriophage by Peracetic Acid and Monochloramine in Municipal Secondary Wastewater Effluent. Environ Sci Technol

697 49. Oguma K, Kita R, Sakai H, Murakami M, Takizawa S. 2013. Application of UV light emitting diodes to batch and flow-through water disinfection systems. Desalination 328:24-30.

700 50. Araud E, DiCaprio E, Ma Y, Lou F, Gao Y, Kingsley D, Hughes JH, Li J. 2016. Thermal inactivation of enteric viruses and bioaccumulation of enteric foodborne viruses in live oysters (Crassostrea virginica). Appl Environ Microbiol 82:2086-2099. trade-offs in the disinfection of wastewater for landscape irrigation: Microplasma 
705 ozonation: Vs. chlorination. Environ Sci Water Res Technol 3:106-118.

706 52. Bustin SA, Benes V, Garson JA, Hellemans J, Huggett J, Kubista M, Mueller R, Nolan T,

707 Pfaffl MW, Shipley GL, Vandesompele J, Wittwer CT. 2009. The MIQE guidelines:

708 Minimum information for publication of quantitative real-time PCR experiments. Clin

$709 \quad$ Chem 55:611-622.

710 53. Yang J, Anishchenko I, Park H, Peng Z, Ovchinnikov S, Baker D. 2020. Improved protein

711 structure prediction using predicted interresidue orientations. Proc Natl Acad Sci U S A

$712 \quad 117: 1496-1503$.

713 